\title{
Antiretroviral Therapy Adherence Level and Associated Factors Among HIV/AIDS Patients in Jimma Zone Government Health Facilities, ART Clinics, South-west Ethiopia
}

\author{
Aregash Hassen*; Yasmin Mohammed \\ Department of Psychology, College of Education and Behavioral Sciences, Jimma University, Ethiopia \\ Email: visitdarusselam2@gmail.com
}

http://dx.doi.org/10.18415/ijmmu.v5i5.535

\begin{abstract}
Optimal and strict adherence to Antiretroviral Viral Therapy a need for over the long period to achieve the goals of ART and obtain maximum benefits of ART. However, PLWHA find it very difficult to take ARVs drug as precisely as they should for a number of reasons. Therefore, this study aimed at examining the level of antiretroviral therapy adherence and identifying possible associated factors for ART adherence behavior in Jimma zone government ART facilities. A facility based cross-sectional study was conducted in the ART clinics of Jimma zone governmental health facilities in which ARV treatment supplied from November 25/2015 - February 30/2016 for a period of 4 months. 352 adult PLWHA (190 female and 162 male) ranged in age from 15-62 years (Mean=37.1, $\mathrm{SD}=8.95)$, with $100 \%$ response rate, were our study participants. Binary logistic regression was used to perform bivariate and multivariate analyses to determine the association between study variables and ART adherence status. 259(73.6\%) participants were adherent $(>=95 \%)$ and $93(26.4 \%)$ were non-adherent $(<95 \%)$ to the prescribed dose of ARV drugs over the past seven days prior to the interview. The main reasons for skipping the prescribed ARV drugs were, busyness (78.5\%), having too many pills $(71 \%)$, felt depressed $(68.8 \%)$, taking the drugs reminded HIV infected (66.7\%), did not want other see $(62.4 \%)$, and felt asleep(60.2\%). The last stepwise regression analysis revealed that, educational status, knowledge of HIV/AIDS, use of additional drugs and access to reliable pharmacy were significantly associated with ART adherence status. So, efforts to maximize ART adherence should focus on addressing these associated significant factors.
\end{abstract}

Keywords: ART Adherence; HIV/AIDS

\section{Introduction}

Worldwide, by the end of 2015, about 36.7 million people were living with Human Immunodeficiency Virus (HIV). Approximately, 17 million people living with HIV were on treatment and annual Acquired Immunodeficiency Syndrome (AIDS) related death decreased by $43 \%$. In eastern and southern Africa- the worlds most affected area, nearly, 10.3 million people were on treatment, in so doing, and AIDS related death decreased by 36\% (UNAIDS., 2016). In Ethiopia, by 2015, a total of 399,380 adults were on Antiretroviral Therapy (ART) (Wang \& his colleagues., 2016); and among those started on Antiretroviral Drugs (ARVs), almost 70\% remained on treatment (Samuel., Jani \& Kassa., 
2016). The introduction of ART in 1996 (Ford., Boulle \& Egger., 2016) and the scale up programs (WHO., 2011) has significantly transformed HIV/AIDS, from once unmanageable disease to a manageable one (Heyer \& Ogunbanjo., 2006).

Though ART has changed the clinical development of HIV infection and making it a chronic manageable disease; yet, optimal and strict ART adherence -over 95\% adherence to ART needed for over the long period (Ammassari., PaolaTrotta \& Mul., 2005; FMOH., 2006). Patients with optimal ART adherence may achieve the goals of ART and obtain maximum benefits of ART such as: maximal and long-lasting suppression of viral replication, reduced destruction of Cluster of differentiation 4 (CD4) cells, prevention of viral resistance, improvement of immune rebuilding, prolong life expectancy and improved quality of life, minimize adverse effects of the treatment and decelerated disease progression (WHO., 2003; Harrigan., Hogg., Dong., 2005; Paterson., Swindells., Mohr., Brester., Vergis., Squire., 2000). Otherwise non-adherence to ART can lead to poor suppression of viral replication, sustained destruction of CD4 cells, progressive deterioration in immune function, disease progression and emergence of viral resistance to one or more antiretroviral medications (Carrieri., Cailleton., Le Moing., Spire., Delllanonica., Bouvet., Raffi., Journot., Moatti., \& APROCO study group., 2001; Gebrezgabher., Kebede., Kindie., Tetemke., Abay \& Gelaw., 2017). In addition, Poor adherence associated with higher mortality rates, higher rates of viral load, lower therapeutic success, and increased hospital days (Health., 2009; Markos., Worku., \& Dave., 2008; Alagaw, Godana, Taha,\& Dejene., 2014; Tiyou., Belachew., Alemseged \& Biadgilign., 2010).

ART is a challenging treatment, which not only involves taking ARV drugs, but total engagement of the patient, that is; understanding HIV/AIDS and ART, preparing for and adhering to a course of ARV therapy, safeguarding proper nutrition, changing life styles, having psychosocial support, comforting care and being considerate for the caregivers of peoples living with HIV/AIDS (WHO., 2006). This means, the patient plays a more dynamic role in his/her treatment and makes a commitment to follow the prescribed regimen as best as possible.

However, many people find it very difficult to take ARVs drug as precisely as they should for a number of reasons. Some of the reasons for common and consistent barriers for ART adherence include: stigma, perceptions of side effects, lack of food, inadequate knowledge of ART, patient reported symptoms, stress, lack of social support, substance use, regimen complexity, self-efficacy for medication taking, depression (Edward., Machtinger \& Bangsber., 2006; Tassie., 2010); gender, having immunological failure, having tuberculosis/HIV co-infection (Gesesew., Ward., Woldemichael., \& Mwanri., 2017; Alagaw et al., 2014).

Even though level of adherence; associated factors and implications have become more and more recognized, studies about this issue still need further investigations particularly in Jimma zone government ART facilities-tremendously scale up to reach people with HIV particularly in rural and semi urban settings. Furthermore, though very few studies attempted to assess antiretroviral therapy discontinuations and identified some possible associated factors (Gesesew et al., 2017; Assefa., Taha., Dejene \& Dube., 2013; Amberbir., Deribe., Hailekiros., Biadglign \& Kebede., 2008; Tiyou et al., 2010). These studies were all of them based on sole, well organized study setting such as Jimma University Specialized Hospital ART clinic or Nekemte Hospital. In addition, these studies merely tried to identify the risk factors and the level of adherence based on secondary data.

Stated the above gap, and emphasizing the importance of antiretroviral therapy adherence, therefore the aim of this research article was to assesses the level of antiretroviral therapy adherence and to identify possible associated factors for ART adherence behavior in Jimma zone government ART facilities. It is vital to comprehend the level of ART adherence level and possible foremost factors for 
ART adherence in order to contextualize intervention plans to retain PLWHA in care and to minimize treatment cost.

\section{Methodology}

To achieve the study objectives- level of adherence and possible associated factors for ART adherence, facility based cross-sectional study design was used. The study was conducted in the ART clinics of Jimma zone governmental health facilities in which ARV treatment supplied from November 25/2015 - February 30/2016 for a period of 4 months.

Jimma zone is one of the 17 zones in Oromia Regional State and the zone's capital city is Jimma town, which is located $350 \mathrm{~km}$ south west of Addis Ababa. According to the Federal Ministry of Health of Ethiopian Health Facility Monthly ART Report of Jimma Zone Health office, of the month July 2014 a total of 3,618 people living with HIV were admitted at different health facilities in the zone; of whom 1,876 were Adults (aged > 14 years) on ART (Monthly Report of Jimma zone Health Office, Unpublished; ORHB. 2013/14).

Even though, there are more than 10 governmental health facilities in semi urban and rural areas of Jimma zone, during the study period we found about three health facilities with well-established ART facilities and the rest are newly established and the number of patients on treatment (patient loads) were less than 100 (Monthly Report of Jimma zone Health Office, Unpublished; ORHB. 2013/14).

The inclusion criteria of the study participants were being HIV/AIDS patient categorized as adult in the national treatment protocol; follow ART treatment at Jimma Zone Health facilities ART clinics; on ART at least for one year and above and willing to participate in the study. More specifically, patients who were not in critical medical and mental illness; and health centers with patient load higher than 100 were entitled for inclusion in the study. Two ART facilities (Agaro and Sekoru health centers) were selected from ART facilities that are well-established and with more than 100 patients and a sample size of 352 patients was calculated using appropriate formula (James., Joe \& Chadwick., 2001). Finally, using, each health facilities patient's loads, the proportion of patients per health facilities were determined. To minimize selection bias that threatens randomization of samples, sample participant selection was made by systematic random sampling technique. This means, every $\mathrm{K}^{\text {th }}$ of participant was selected using the ART clinic registration book as a sampling frame. The first patient was selected by lottery method. For patients who were not fulfilling the inclusion criteria, the next patient was selected. In fact, before the selection of study participants, ethical clearance was obtained from Post-graduate and Research Coordinating Office, College of Education and Behavioral Science of Jimma University; and Oromia Regional Health Office. Finally permission to collect information from the patients had been secured from Jimma Zone Health Office and the head of selected ART facilities. Participants were asked to give their consent whether they are willing to participate in the study and this has no influence to the care they were given for.

The data were collected by two trained and supervised data collectors who are working at the ART clinics data base and senior staff of each ART clinic, after common understanding on the questionnaire and checklists were reached. Eligible patients were interviewed for 20-25 minutes. The questionnaire used in this study was developed and in some case adapted from the existing literature and previous research works. The questionnaire was translated to local language (Afan-Oromo). The questionnaire assessed patients' socio-demographic characteristics; psychosocial attributes; health care system, and health care providers team related variables. 
The selected participants were asked about their self-reported dose adherence. They were asked whether any antiretroviral medication had been skipped in the previous seven days. In order to minimize recall bias patients were asked about adherence of that day, the previous day, the previous three days or the previous seven days. A person was adherent if he/she took $\geq 95 \%$ of the prescribed doses correctly. For this research, we used dose adherence in the previous seven days.

The data collected from the respondents were cleaned, coded, entered and analyzed using latest version of SPSS 21. Self-reported dose adherence to all antiretroviral agents were summarized as the ratio of the average daily number of antiretroviral medications adhered correctly according to the standard instructions over the total number of antiretroviral medication prescribed. Cross tabulation for data summary and differences in adherence status were tested using chi-square and student's t test. Binary logistic regression was used to perform bivariate and multivariate analyses to determine the association between study variables and ART adherence status.

Before multivariate analysis was performed univariate analysis was done to check for crude association between the dependent variable (ART adherence status) and individual independent variables (gender, educational status, marital status, working situation, active substance use, family support, and so on).

Then, multivariate analysis with all independent variables with p-value smaller than or larger than but closer to the significance level (0.05) were entered into the model to identify independent predictors while controlling for confounders. As many of those, predictor variables were dependent on each other, forward stepwise procedure, which includes one new explanatory variable at each step, specifically the most associated with the dependent variable while being, at the same time, independent of the explanatory variables already included in the model.

\section{Results}

\section{Participant's Socio-Economic and Baseline Clinical Characteristics}

352 adult PLWHA (190 female and 162 male) ranged in age from 15-62 years (Mean=37.1, SD= 8.95), with $100 \%$ response rate, were our study participants. Participants were predominantly Muslim in religion and Oromo in ethnicity. Nearly more than half (50.9\%) participants were married, 63.9\% were living with their family. Majority $49.4 \%$ reported primary/read and write educational level and 167 (47.4\%) had monthly income of whom, 83.2\% earned less than 1000 Birr per month. In addition, the participants initial $\mathrm{CD}_{4}$ counts ranged from 45-1589 (Mean=285.5, $\mathrm{SD}=178.4$ ); and had been using ART for 1 to 12 years $($ Mean=5.68, $\mathrm{SD}=3.29)$.

Of the total 352 participants, 259(73.6\%) were adherent (>=95\%) and 93(26.4\%) were nonadherent (<95\%) to the prescribed dose of ARV drugs over the past seven days prior to the interview. Of the total 93 non-adherent participants, majority 61(65.6\%) were females. Out of 93 non adherent participants, 25(26.9\%) cannot read and write; 29(31.2\%) can read and write; and 28(30.1\%) were attend primary education. 39(41.9\%) of non-adherent patients were married and 48(51.6\%) were living with their family. In addition, 73(20.7\%) of the participants were active substance users, of whom, 28(30.1\%) were from non-adherent group and most of them $60.7 \%$ used alcohol.

Even though, the observed differences were non-significant ( $>00.05), 34.9 \%$ of the participants do not get sense of care, safety, and security of support from their family, co-workers, and others people in their community, of whom $29 \%$ were non adherent to ART. In addition, $21 \%$ do not feel confident about their ability to take the medication accordingly to the regimen or have some kind of difficulties, of whom $29 \%$ were non adherent to ART; and the differences were significant $(\mathrm{p}<0.05)$. 
Out of the 93 participants who failed to adhere ART, the main reasons for skipping the prescribed ARV drugs were, busyness (78.5\%), having too many pills (71\%), felt depressed (68.8\%), taking the drugs reminded HIV infected (66.7\%), did not want other see $(62.4 \%)$, and felt asleep $(60.2 \%)$.

172 of the total participants were not aware of HIV/AIDS when they first met their health care providers, of whom $29 \%$ were non adherent. More than half $(51.1 \%)$ heard about ARV during their illness, of whom $32.2 \%$ were among the non-adherent. In addition, $92.9 \%$ did get the information about ARV from healthcare professionals, however $24.8 \%$ were non adherent. Half of the participants did not know the importance of ART adherence before they start ART. A significant number of the participants $78(22.2 \%)$ said no to the question whether ART delay AIDS or not, of whom $46.2 \%$ were non-adherent. Again $88(25 \%)$ of the participants were answered no to the question whether an HIV infected person could live longer or not while he/she using ART, of whom $48.9 \%$ were non-adherent. Regarding the time specification for ART, more than half $(61.6 \%)$ said there no specified time to take ART of whom $44.1 \%$ were non-adherent. In addition to, 58.5\% did not feel comfortable when taking ART in front of others, for the $23.3 \%$ the schedule did not fit for their daily routine activities, however, $28.7 \%$ had felt any side effect to ART, and $74.4 \%$ of the participants were taking additional medication with ARV drugs, of whom $66.7 \%$ of the non-adherent were among them. The above mentioned differences were significant at $\mathrm{p}<0.05$.

The results of the relationship between healthcare providers' showed that, $90.9 \%$ of the participants were satisfied with the clinicians' (health professional) services, however, $17 \%$ did not feel the health care providers treating them are capable, $19.6 \%$ did not have open communication with them and $5.1 \%$ also said they did not get the education or assistance they need during their visit. In addition, the results of health care system and clinical settings showed $87.2 \%$ had access to reliable pharmacy any time they want, $81.8 \%$ and $84.4 \%$ are satisfied by the improvements they obtain, and in scheduling appointments and confidentiality of the treatment unit, respectively. The observed differences were statistically significant at $\mathrm{p}<0.05$ see (Table 1$)$.

Table 1 Factors related the healthcare providers, health care system and clinical setting of HIV Infected Patients in Selected Governmental ART Centers Jimma Zone South-Western Ethiopia, 2016

\begin{tabular}{|c|c|c|c|c|}
\hline \multirow[t]{2}{*}{ Characteristics } & & \multicolumn{2}{|c|}{ Status of Adherence } & \multirow[t]{2}{*}{ Total } \\
\hline & & $\begin{array}{l}\text { Non- } \\
\text { Adherent }\end{array}$ & Adherent & \\
\hline Satisfaction by the clinicians? & Yes & $79(84.9 \%)$ & $241(93.1 \%)$ & $320(90.9 \%) *$ \\
\hline (health professional) service & No & $14(15.1 \%)$ & $18(6.9 \%)$ & $32(9.1 \%)$ \\
\hline Feeling the health care & Yes & $67(72 \%)$ & $225(86.9 \%)$ & $292(83 \%) * *$ \\
\hline providers capable & No & $26(28 \%)$ & $34(13.1 \%)$ & $60(17 \%)$ \\
\hline Having open communication & Yes & $65(69.9 \%)$ & $218(84.2 \%)$ & $283(80.4 \%) * *$ \\
\hline with health care providers & No & $28(30.1 \%)$ & $41(15.8 \%)$ & $69(19.6 \%)$ \\
\hline Obtaining the education or & Yes & $83(89.2 \%)$ & $251(96.9 \%)$ & $334(94.9 \%) * *$ \\
\hline assistant during visits & No & $10(10.8 \%)$ & $8(3.1 \%)$ & $18(5.1 \%)$ \\
\hline Access to reliable pharmacy & Yes & $69(74.2 \%)$ & $238(91.9 \%)$ & $307(87.2 \%) * * *$ \\
\hline any time & No & $24(25.8 \%)$ & $21(8.1 \%)$ & $45(12.8 \%)$ \\
\hline Satisfaction by the changes/ & Yes & $62(66.7 \%)$ & $226(87.3 \%)$ & $288(81.8 \%) * * *$ \\
\hline improvements she/he obtains & No & $31(33.3 \%)$ & $33(12.7 \%)$ & $64(18.2 \%)$ \\
\hline Satisfaction in the scheduling & Yes & $63(67.7 \%)$ & $234(90.3 \%)$ & $297(84.4 \%))^{* * *}$ \\
\hline $\begin{array}{l}\text { appointments } \\
\text { confidentiality of and } \\
\text { treatment unit }\end{array}$ & No & $30(32.3 \%)$ & $25(9.7 \%)$ & $55(15.6 \%)$ \\
\hline Total & & $26.4 \%)$ & $259(73.6 \%)$ & $352(100 \%)$ \\
\hline
\end{tabular}


Univariate analysis was done to check for crude association between the dependent variable (ART adherence status) and individual independent variables which is expected to be associated with the dependent based on existing knowledge. Therefore, from socio-demographic characteristics sex, marital, education and person's family status showed significant association with ART adherence status. Among the psycho-social variables, use of active substances and confidence about their ability to take the medication accordingly to the regimen or having some difficulties, were associated with ART adherence. From the illness change and health status variables, aware of HIV/AIDS when they first met their doctor, the time they did hear about ARV, the sources of information about ARV, were significantly associated with ART adherence status. From patient providers and clinical setting variables, satisfaction with the clinicians' (health professional) service, feeling the health care providers treating them are capable, open communication with HCP treating them, having reliable pharmacy, satisfaction by the change they get, and with scheduling were significantly associated with the status of ART.

The variables chosen by the forward stepwise method of the last model all have significant $(\mathrm{p}<0.05)$ changes in $-2 \mathrm{log}$-likelihood. Moreover, the last forward stepwise regression analysis model showed education status of the participants from socio-demographic, knowledge of HIV/AIDS when they first met with their health care providers such as the benefit and importance of adherence before starting ART and those who use additional drugs from illness change and satisfaction with clinicians and access to reliable pharmacy any time they need from healthcare providers and clinical settings were significantly associated with ART adherence status. See (Table 2).

However, no significant independent association ( $p>0.05)$ were found between sex of respondents, marital status, person's living situations, active substance usage, side effects of ARV drugs, having open communication with health care providers, obtaining the education assistance during their visit, and satisfaction by the changes they get from treatments, and ART adherence.

Table 2 the log Likelihood test of HIV Infected Patients in Selected Governmental ART Centers Jimma Zone South-Western Ethiopia, 2016

\begin{tabular}{lrr}
\hline Variable & Model Log Likelihood & $\begin{array}{c}\text { Change in -2 Log } \\
\text { Likelihood }\end{array}$ \\
\hline Education status & & $12.522^{* * *}$ \\
Aware HIV/AIDS & -151.553 & $18.989^{* * *}$ \\
Aware of benefit ARV drugs & -154.786 & $25.540^{* * *}$ \\
Importance of adherence & -158.062 & $15.749^{* * *}$ \\
Taking ART livelong & -153.167 & $5.427^{*}$ \\
Low WBC entitled ART & -148.006 & $6.696^{* *}$ \\
Additional drugs & -148.640 & $9.491^{* *}$ \\
Satisfaction with clinicians & -150.038 & $4.777^{*}$ \\
Reliable pharmacy & -147.681 & $3.764^{*}$ \\
\hline
\end{tabular}

$*$ p-value $<0.05, * * \mathrm{p}<0.01, * * * \mathrm{p}<0.001$

Therefore, result showed (Table 2), those who were aware of the benefit of ARV drugs were 12.904 times more likely to be adherent to ART (AOR=12.904, 95\% CI 4.490, 37.080). Furthermore, those who said taking ART make live longer (AOR=2.175, 95\% CI 1.134, 4.173), those who said only the body's defense system extremely low to be a person to reserve ART (AOR= 2.874, 95\% CI 1.29, 6.407), were more likely to be adherent to ART than those who did not, respectively. Moreover, those who were taking additional drugs with $\mathrm{ARV}(\mathrm{AOR}=2.929,95 \% \mathrm{CI} 1.463,5.865)$, those who were 
satisfied with the clinicians' (health professional) service (AOR $=2.876,95 \%$ CI $1.133,7.301$ ) and those who had access to reliable pharmacy any time they want ( $\mathrm{AOR}=2.443,95 \% \mathrm{CI} 0.990,6.032)$ were more likely to be adherent to ART than those who did not, respectively (Table 3 ).

However, according to multivariate logistic regression analysis adherence to ART were less by $72.3 \%$ among participants of primary education level $(\mathrm{AOR}=0.277,95 \%$ CI $0.114,0.677)$ than participants of high school and above and also those who were aware of HIV/AIDS when they first meet their HCP were less likely to be adherent $(\mathrm{AOR}=0.253,95 \% \mathrm{CI} 0.131,0.488)$.

Table 3 Factors associated with adherence to ART among HIV Infected Patients in Selected Governmental ART Centers Jimma Zone South-Western Ethiopia, 2016

\begin{tabular}{|c|c|c|c|c|c|}
\hline Variables & & $\begin{array}{l}\text { Non- } \\
\text { Adherent } \\
\mathrm{N}(\%)\end{array}$ & $\begin{array}{l}\text { Adherent } \\
\mathrm{N}(\%)\end{array}$ & $\begin{array}{l}\text { Crude odds ratio ( } 95 \% \\
\text { C.I.) }\end{array}$ & $\begin{array}{l}\text { Adjusted odds ratio } \\
(95 \% \text { C.I. })\end{array}$ \\
\hline High school and above & & & & Reference & References \\
\hline Cannot read and write & & $25(26.9 \%)$ & $71(27.4 \%)$ & $0.440(.201, .962)$ & $1.083(.395,2.968)$ \\
\hline Read and write only & & $29(31.2 \%)$ & $43(16.6 \%)$ & $0.230(0.104,0.507)$ & $0.664(.257,1.721)$ \\
\hline Primary educations & & $28(30.1 \%)$ & $74(28.6 \%)$ & $0.409(0.190,0.884)$ & $0.277(0.114,0.677) * *$ \\
\hline \multirow{2}{*}{ Aware HIV/AIDS } & Yes & $66(71 \%)$ & $114(44 \%)$ & $0.322(0.193$ to 0.536$)$ & $0.253(0.131,0.488) * * *$ \\
\hline & No & $27(29 \%)$ & $145(56 \%)$ & Reference & Reference \\
\hline \multirow[t]{2}{*}{ Aware of benefit } & Yes & $74(79.6 \%)$ & $249(96.1 \%)$ & $6.393(2.848,14.350)$ & $12.904(4.49,37.08)^{* * *}$ \\
\hline & No & $19(20.4 \%)$ & $10(3.9 \%)$ & Reference & Reference \\
\hline \multirow{2}{*}{ Importance of adherence } & Yes & $69(74.2 \%)$ & $107(41.3 \%)$ & $0.245(0.145,0.414)$ & $0.283(0.147,0.545)^{* * *}$ \\
\hline & No & $24(25.8 \%)$ & $152(58.7 \%)$ & Reference & Reference \\
\hline \multirow{2}{*}{ Taking ART livelong } & Yes & $50(53.8 \%)$ & $214(82.6 \%)$ & $4.090(2.434,6.873)$ & $2.175(1.134,4.173) *$ \\
\hline & No & $43(46.2 \%)$ & $45(17.4 \%)$ & Reference & Reference \\
\hline \multirow{2}{*}{ Low WBC entitled ART } & Yes & $65(69.9 \%)$ & $224(68.5 \%)$ & $2.757(1.561,4.868)$ & $2.874(1.29,6.407) *$ \\
\hline & No & $28(30.1 \%)$ & $35(13.5 \%)$ & Reference & Reference \\
\hline \multirow[t]{2}{*}{ Additional drugs } & Yes & $62(66.7 \%)$ & $201(77.6 \%)$ & $1.733(1.029,2.917)$ & $2.929(1.463,5.865) * *$ \\
\hline & No & $31(33.3 \%)$ & $58(22.4 \%)$ & Reference & Reference \\
\hline \multirow[t]{2}{*}{ Satisfaction with clinicians } & Yes & $79(84.9 \%)$ & $241(93.1 \%)$ & $2.373(1.128,4.989)$ & $2.876(1.133,7.301)^{*}$ \\
\hline & No & $14(15.1 \%)$ & $18(6.9 \%)$ & Reference & Reference \\
\hline \multirow[t]{2}{*}{ Reliable pharmacy } & Yes & $69(74.2 \%)$ & $238(91.9 \%)$ & $3.942(2.070,7.506)$ & $2.443(0.99,6.032) *$ \\
\hline & No & $24(25.8 \%)$ & $21(8.1 \%)$ & Reference & \\
\hline
\end{tabular}

$* \mathrm{p}$-value $<0.05, * * \mathrm{p}<0.01, * * * \mathrm{p}<0.001$, C.I. $=$ Confidence Interval

\section{Discussion}

In this study, the overall adherence to ART was $73.6 \%$ were adherent ( $>=95 \%)$ and $26.4 \%$ were non-adherent $(<95 \%)$ to the prescribed dose of ART drugs over the past seven days prior to the interview. This study is consistent with the results of the study conducted in three provinces of Vietnam which scored 74.1\% adherent (Bach Xuan Tran et al. 2013). However, dose adherence in the present study area is lower than that reported in Addis Ababa (81.2\%) (Tadios \& Davy., 2006); Jimma University Specialized hospital (>95\%) (Tiyou et al., 2010), wolaita sodo hospital (87.4\%) (Alagaw et al., 2014) and a study by Sarna \& colleuges, (2008) in Kenya, Mombassa where self- reported dose adherence were 93.4\%. One possible reason for these disparities could be that these studies used different methods to measure ART adherence; some used self-report of missed doses from few weeks to months while others used pill count. 
The present study found that forgetfulness was the most frequently claimed reason for missing doses, which is similar with study findings reported in Mombasa, Kenya in which the main reason for missing therapy were being busy and forgetting (Sarna et al., 2008). Similarly., other studies in Ethiopia reported that forgetting was the main reason for missing doses in addition to other reasons like being busy and away from the home (Chaka et al., 2016; Tiyou et al., 2010; Alagaw et al., 2014 ).

The results of this study showed significant association concerning the knowledge and attitude such as, aware of the benefit of ARV drugs, aware of taking ART make live longer, and aware of who to be assigned or to start ART such as knowing that the need for the body's defense system extremely or very low, aware of taking additional drugs with ARV for opportunistic infections. This goes in line with a review provided evidence of the effectiveness of patient support and education interventions, reporting that interventions targeting practical medication management skills were associated with improved adherence outcomes (Simoni et al., 2008).

In addition, the significant association between ART adherence and satisfaction with the clinicians' (health professional) service and; having access to reliable pharmacy any time the patient need found in this study is in line with the findings of the study conducted in Oromia region public health institutions which showed one of the situations for improvement of ART adherence were the health professional responsibility to have a good relationship with patients (Sileshi Garoma Abeya \& his colleagues., 2017; Morten., Ctherin., Kundai., Constance \& Simon., 2011). The review done by Morten et al, (2011) which is in line with the findings of this study, indicated that access and health care provider relationship were found to be important factors that determined satisfactory adherence to ART. That means, the findings of this study and others highlights the importance of patients compliant to the standards of the good adherence characteristics and the required level of relationship building between patients and health care professionals. To conclude meaningful and supportive relationship between the patient and health care provider can help to overcome significant barriers to adherence (WHO., 2008; Melissa \& his colleagues., 2009).

Similar to previous studies, (Tadios \& Davy., 2006; Bach Xuan Tran et al., 2013; Amberbir et al., 2008; Tiyou et al., 2010; Alagaw et al., 2014), in the multivariate analysis of this study, no significant independent association were found between sex of respondents, marital status, person's living situations, active substance usage and ART adherence ( $p>0.05$ ). Although, many other potential variables were included in this study, they did not show consistent associations with status of adherence.

\section{Conclusion and Implication}

The rate of ART adherence in the study area was lower. Participants' education status, knowledge and attitude of HIV/AIDS when they first met with their health care providers, using additional drugs for other infections, satisfaction with health care provider and access to reliable pharmacy any time they need were significantly and independently associated with ART adherence status. The most mentioned reasons for missing prescribed ARV drugs dose were being busy, having too many pills, felt depressed, taking the drug reminded HIV infected, did not want other see and felt asleep. The findings of this study suggested that, timely detection of non-adherence behaviors and appropriate monitoring of patients' difficulties with ART could potentially help patients to maintain adherence and therefore improve the treatment outcome. Also, the knowledge and attitude of the patients towards the course of HIV/AIDS should be given due emphasis. Finally, substantial and supportive relationship between the patient and health care provider needed to increase the status of ART adherence. Since ART adherence varies over time and between individuals. Therefore, for further research, we recommend that, using multiple measures prospective and mixed studies, including qualitative and quantitative research; cross-sectional 
and longitudinal designs; and taking patients from delivery sites run by both the public and private sector, are needed to assess level of adherence and the factors associated with ART adherence.

\section{Acknowledgment}

We are indebted to Jimma University, College of Education and Behavioral Science Postgraduate and Research Coordinator office for funding this research work and facilitating necessary activities. Oromia Regional Health Bureau earns exceptional recognition for the ethical approval and permission letter to conduct the study. We are grateful for Jimma Zone Health Bureau for letters of permission and professional support; and other line offices and individuals who played significant roles in availing required information without which this work would not have been accomplished. Besides, we appreciate the perspective contributions of all supervisors, data collectors and study participants.

Competing interest

The authors have declared that no competing interests.

\section{References}

Alagaw, A., Godana, W, Taha, M., \& Dejene, T. (2013). Factors Associated with Antiretroviral Treatment Adherence among Adult Patients in Wolaita Soddo Hospital. J Trop Dis 1, 125. Doi: 10.4172/2329-891X.1000125.

Amberbir, A., Woldemichael, K., Getachew, S., Girma, B., \& Deribe, K. (2008). Predictors of Adherence to Antiretroviral Therapy Among HIV Infected Persons: A Prospective Study in Southwest Ethiopia. Available from: http://www.pubmedcentral.nih.gov/articlerender.fcgi?artid=2518153\&tool=pmcen trez.

Ammassari, A., PaolaTrotta, M., Mul, R. (2005). Correlates and Predictors of Adherence to HAART. Journal of Acquired Immune Deficiency Syndrome, 31(3): 123- 127.

Asefa T, Taha M, Dejene T, Dube L. (2013). Determinants of Defaulting from Antiretroviral Therapy Treatment in Nekemte Hospital, Eastern Wollega Zone, Western Ethiopia. Public Health Research, 3(5): $130-5$.

Assefa, Y., Worku, A., Wouters, E., Koole, O., Hailemariam, D., Van Damme, W. (2012). Simplified Tools for Measuring Retention in Care in Antiretroviral Treatment Program in Ethiopia: Cohort and Current Retention in Care. PLoS One, 7(6): e38555. Doi:10.1371/journal.pone.0038555.

Ayalu, A.R. \& Sibhatu, B. (2012). Determinants of Adherence to Antiretroviral Therapy Among HIVInfected Patients in Africa. AIDS Research and Treatment, 20.

Ayele A, Tefera B, Fisehaye A, Sibhatu B. (2010). Predictors of Adherence to Antiretroviral Therapy Among People Living with HIV/AIDS in Resource Limited Setting of Southwest Ethiopia. AIDS Research and Therapy, 7: 39.

Bach X. T., Long T. N., Nga H. N., Quynh V. H. and Jongnam H. (2013). Determinants of Antiretroviral Treatment Adherence Among HIV/AIDS Patients: A Multisite Study. Glob Health Action, 6: 19570http://dx.doi.org/10.3402/gha.v6i0.19570. 
Carrieri, P., Cailleton, V., Le Moing, V., Spire. B., Delllanonica, P., Bouvet, E., Raffi, F., Journot, V., Moatti, J.P., \& APROCO Study Group. (2001). The Dynamic of Adherence to Highly Active Antiretroviral Therapy: Results from the French National APROCO cohort. J Acquir Immune Defiic Syndr, 28: 232-39.

Chaka, T. E., Abeya, S. G., Adlo, A. M., Abebe, T. W., Hamuse, S. D., et al. (2016). Antiretroviral Therapy: Level of Adherence and Its Determinants Among Patients on Treatment in Different Health Facilities. A Cross Sectional Study in Oromia Regional State, Ethiopia. J AIDS Clin Res, 7(629). Doi: 10.4172/2155-6113.1000629.

Chesney, M. A. (2000). Factors Affecting Adherence to Antiretroviral Therapy. Clinical Infectious Diseases, 30(2): 171-176.

CSA. (2011). Ethiopia Demographic and Health Survey 2011. Addis Ababa, Ethiopia.

Deribe K, Hailekiros F, Biadgilign S, Amberbir A, Beyene BK. (2008). Defaulters from Antiretroviral Treatment in Jimma University Specialized Hospital, Southwest Ethiopia. Tropical Medicine \& International Health, 13(3): 328-33.

FMOH. (2006). Disease Prevention and Control Department, AIDS in Ethiopia, 6th Edition, Addis Ababa. FMOH.

Ford N, Boulle A, Egger M. (2016). Accounting for and Responding to HIV-Associated Mortality. AIDS (London, England), 30(3): 521-3.

Gesesew HA, Ward P, Woldemichael K, Mwanri L. (2017). Prevalence, Trend and Risk Factors for Antiretroviral Therapy Discontinuation Among HIV-Infected Adults in Ethiopia in 2003-2015. PLoS ONE, 12(6): e0179533. https://doi.org/10.1371/journal.pone.0179533.

Health, F. H. P. and C. O. F. M. (2009). Guidelines for Implementation of HIV/AIDS Case Management in Ethiopia: 1-71.

Heyer, A., \& Ogunbanjo, G. A. (2006). Adherence to HIV Antiretroviral Therapy. Part I: A Review of Factors that Influence Adherence. Open forum.

James E. B., Joe W. K., and Chadwick C. (2001). Organizational Research: Determining Appropriate Sample Size in Survey Research. Information Technology, Learning, and Performance Journal, 19(1).

Kalibala Samuel, Nrupa Jani and Getachew Kassa. (2016). "Algorithms for HIV Care and Treatment in Ethiopia,” HIVCore Final Report. Washington, DC: USAID | Project Search: HIVCore.

Markos, E., Worku, A. \& Davey, G. (2008). Adherence to ART in PLWHA at Yirgalem Hospital, South Ethiopia. Ethiop. J. Health Dev., 22(2): 174-179.

Melissa, W., Maman, S., Earp, J. A., Eng, E., Setel, P., et al. (2009). It's All the Time in My Mind: Facilitators of Adherence to Antiretroviral Therapy in a Tanzanian Setting. Social Science \& Medicine, 68: 1793-1800.

Mills, E. J., Nachega, J. B., Bangsberg, D. R., Singh, S., Rachlis, B., et al. (2006). Adherence to HAART: A Systematic Review of Developed and Developing Nation Patient-Reported Barriers and Facilitators. 
PLoS medicine, 3(11): 438. Available at: http://www.pubmedcentral.nih.gov/articlerender.fcgi?artid= 1637123\&tool=pmcentrez rendertype=abstract [Accessed May 26, 2013].

Morten S, Catherine C, Kundai N, Constance N and Simon G. (2011). Contextual and Psychosocial Influences on Antiretroviral Therapy Adherence in Rural Zimbabwe: Towards A Systematic Framework for Program Planners. Int J Health Plann Mgmt 2011; 26: 296-318.

ORHB. Oromia Regional Health Bureau Report 2013/14.

Paterson, D.L., Swindells, S., Mohr, J., Brester, M., Vergis, E., Squire, C. et al., (2000). Adherence to Protease Inhibitor Therapy and Outcomes in Patients with HIV Infection. Ann Intern Med, 133: 21-30.

Sarna, A., Luchters, S., Geibel, S., Chersich, M.F., Munyao, P., Kaai, S., et al. (2008). Short- and LongTerm Efficacy of Modified Directly Observed Antiretroviral Treatment in Mombasa, Kenya: A RandoMized trial. J Acquir Immune Defic Syndr, 48: 611-619.

Sileshi Garoma Abeya, Abebe Megerso Adlo, Tolesa Eticha Chaka, Tilay Worineh Abebe, et al., (2017). Anti-Retroviral Therapy in Public Health Institutions of Oromia Region: A qualitative study. Public Health International, 2(1): 51-59.

Simoni et al. 2008. Strategies for Promoting Adherence to Antiretroviral Therapy: A Review of the Literature. Current Infectious Disease Report, 10: 515-521

Tadios Y, Davey G. (2006). Antiretroviral Treatment Adherence and Its Correlates Among People Living with HIV/AIDS on Highly Active Antiretroviral Therapy in Addis Ababa, Ethiopia. Ethiopian Medical Journal, 44(2): 237-244.

UNAIDS. (2016). Global AIDS Update, 2016.

Wang H, Wolock TM, Carter A, Nguyen G, Kyu HH, Gakidou E, et al. (2016). Estimates of Global, Regional, and National Incidence, Prevalence, and Mortality of HIV, 1980-2015: The Global Burden of Disease Study 2015. Lancet HIV, 3(8): e361-87.

WHO. (2003). Adherence to Long-Term Therapy: Evidence for Action. Geneva.

WHO. (2006). Antiretroviral Therapy for HIV Infection in Adults and Adolescents. Recommendations for a Public Health Approach.

WHO. (2011). Towards Universal Access: Scaling up Priority HIV/AIDS Interventions in the Health Sector. Progress Report 2010. Geneva.

WHO.(2008). Determinants of Adherence to Antiretroviral Treatment: An Explorative Study at Health Facilities in Ethiopia and Uganda. INRUD.

\section{Copyrights}

Copyright for this article is retained by the author(s), with first publication rights granted to the journal.

This is an open-access article distributed under the terms and conditions of the Creative Commons Attribution license (http://creativecommons.org/licenses/by/4.0/). 